\title{
Current and future therapeutic approaches in narcolepsy
}

\section{Valérie Cochen De Cock' \& Yves Dauvilliers ${ }^{\dagger 1}$}

'National Reference Network for Narcolepsy, Sleep-Disorders Center, Department of Neurology, Hôpital Gui de Chauliac, INSERM U1067, UM1, Montpellier, France

†Author for correspondence: Tel.: +33 467337277 n. Fax: +33 467337285 = y-dauvilliers@chu-montpellier.fr

Narcolepsy with cataplexy (NC) is a disabling orphan sleep disorder characterized by excessive daytime sleepiness, cataplexy and other dissociated manifestations of rapid eye movement sleep (hypnagogic hallucinations and sleep paralysis), as well as frequent movement and awakening during night-time sleep. In this article, we will describe the main symptoms and the current and future treatments of NC. Pathophysiological studies have shown that NC is caused by the early loss of neurons in the hypothalamus that produce hypocretin/orexin, a wakefulnessassociated neurotransmitter present in cerebrospinal fluid. The cause of neural loss could be autoimmune since most patients have the human leukocyte antigen $D Q B 7^{*} 0602$ allele that predisposes individuals to $\mathrm{NC}$. The treatment of narcolepsy has evolved over the past few years with the widespread use of modafinil for daytime sleepiness, antidepressants for cataplexy and $\gamma$-hydroxybutyrate (sodium oxybate) for both symptoms. Potential development of new wake-promoting drugs, anticataplectic medications, slow-wave sleep-enhancing treatments, hypocretin-replacement therapy and immunotherapy at early stages of the disease needs to be evaluated in the near future.

\section{Medscape}

\section{Medscape: Continuing Medical Education Online}

This activity has been planned and implemented in accordance with the Essential Areas and policies of the Accreditation Council for Continuing Medical Education through the joint sponsorship of Medscape, LLC and Future Medicine Ltd. Medscape, LLC is accredited by the ACCME to provide continuing medical education for physicians.

Medscape, LLC designates this Journal-based CME activity for a maximum of 1 AMA PRA Category 1 Credit(s) ${ }^{\mathrm{TM}}$. Physicians should claim only the credit commensurate with the extent of their participation in the activity.

All other clinicians completing this activity will be issued a certificate of participation. To participate in this journal CME activity: (1) review the learning objectives and author disclosures; (2) study the education content; (3) take the post-test with a 70\% minimum passing score and complete the evaluation at www.medscape.org/journal/fnl; (4) view/print certificate.

\section{Release date: 28 October 2011; Expiration date: 28 October 2012}

\section{Learning objectives}

Upon completion of this activity, participants should be able to:

- Describe the clinical characteristics of narcolepsy with cataplexy (NC) as based on the review

- Describe current treatments for NC as based on the review

- Describe treatments for NC likely to be available in the future as based on the review

\section{Financial \& competing interests disclosure}

Editor: Elisa Manzotti, Editorial Director, Future Science Group. Disclosure: Elisa Manzotti has disclosed no relevant financial relationships.

Authors and Credentials: Valérie Cochen De Cock, National Reference Network for Narcolepsy, Sleep-Disorders Center, Hôpital Gui de Chauliac, INSERM U1061, Montpellier, France. Disclosure: Valérie Cochen De Cock has received honoraria as an investigator from Bioprojet. Yves Dauvilliers, National Reference Network for Narcolepsy, Sleep-Disorders Center, Hôpital Gui de Chauliac, INSERM U1061, Montpellier, France. Disclosure: Yves Dauvilliers has consulted for UCB Pharma, Cephalon, Bioprojet and Novartis. 
No writing assistance was utilized in the production of this manuscript.

CME author: Laurie Barclay, Freelance writer and reviewer, Medscape, LLC. Disclosure: Laurie Barclay, MD, has disclosed no relevant financial relationships.

Narcolepsy with cataplexy (NC) is a rare sleep disorder. The main symptom is excessive daytime sleepiness, but patients can also develop abnormal rapid eye movement (REM) sleep manifestations including cataplexy, sleep paralysis and hypnagogic hallucinations. Cataplexy is a partial or complete loss of muscle tone triggered by strong emotions [1-4]. The age at onset ranges from early childhood to 50-60 years of age with a bimodal distribution, including a large peak around 15 years and a smaller peak at approximately 36 years of age [5]. Recent studies have shown that there is a marked decrease in hypocretin-1 levels in the cerebrospinal fluid (CSF) of patients with narcolepsy and a decrease in the number of hypocretin neurons in post-mortem brain tissues of narcolepsy subjects [6-9]. Most studies suggest that the loss of hypocretin-containing neurons in NC might be attributable to an autoimmune process.

Narcolepsy with cataplexy is the most severe example of sleepiness in human beings. Its treatment is symptomatic. It consists of stimulant drugs (mostly dopaminergic) to suppress daytime sleepiness and sleep attacks, antidepressants (mostly noradrenergic) for cataplexy and other REM-associated symptoms, occasionally hypnotics for disturbed night-time sleep and $\gamma$-hydroxybutyrate (GHB) for all three symptoms [10]. More recent treatments including new stimulants and immune-based therapy, but hypocretin-replacement therapy is also currently being developed.

\section{Excessive daytime sleepiness}

In most cases, daytime sleepiness is the first symptom to occur in NC. It is also the most disabling symptom and the most frequent cause for consultation. Daytime sleepiness occurs daily, recurring typically every $2 \mathrm{~h}$, but can vary widely. Sleepiness increases when the patient is physically inactive. Sleep episodes are mostly irresistible, usually short and are frequently associated with dreaming and a feeling of refreshment. During the day, patients may also present automatic behaviors (e.g., they continue to talk but say something inappropriate or they continue to write but change the topic). Sleepiness is confirmed by the Multiple Sleep Latency Tests (MSLTs). The MSLTs consist of five nap opportunities, scheduled at 2-h intervals, starting $1.5-3 \mathrm{~h}$ after awakening. The patient receives the instruction not to fight against sleep. Psychotropic drugs must be discontinued for at least 2 weeks (depending on the half-life) before the recording. Each test is terminated after a 15 -min sleep period or after $20 \mathrm{~min}$ if the patient does not fall asleep. Both sleep and REM sleep latencies are measured. Mean sleep latency below $8 \mathrm{~min}$ confirms excessive daytime sleeping. Latencies below $5 \mathrm{~min}$ indicate severe sleepiness. The efficacy of the treatments given to improve sleepiness should always be checked clinically by the improvement on the Epworth Sleepiness Scale, but also by objective measures such as the Maintenance of Wakefulness Test (MWT). The MWT assesses the patient's ability to maintain wakefulness rather than their drive to fall asleep. The patient is seated comfortably in bed, with low lighting placed behind them. During two or four daytime 20 or 40-min sessions, depending on the protocol used, the patient is asked to stay awake as long as possible [11,12]. The test ends either after $15 \mathrm{~s}$ of any stage of sleep, indicating the insufficient ability to fight against sleep. The most sensible four-trial 40-min MWT protocol revealed a mean sleep latency at $30.4 \pm 11.2 \mathrm{~min}$ for normal controls and a latency below $19 \mathrm{~min}$ (limit of $95 \% \mathrm{CI}$ ) as abnormal [11,12]. The MWT is rarely used as a real test of sleepiness but rather to measure the effectiveness of treatment, especially for research or legal purposes, particularly in cases of driver's license suspension.

Several psychomotor tests based on reaction times, such as the Psychomotor Vigilance Task (PVT) and/or the Oxford Sleep Resistance Test, may be used to evaluate performance decrements due to excessive daytime sleepiness [13]. PVT is a 10 -min reaction time task in which the subject has to press a button as rapidly as possible when a stimulus appears for a few milliseconds scrolling past in the window of the device. This test quantifies the response latency to the stimulus, with data being validated with other tests such as the MSLT in normal controls and sleep-deprived volunteers. The Oxford Sleep Resistance Test consists of four 40-min long trials during which there are multiple light-emitting diode signal presentations. The subject being tested needs to respond to each signal with a simple button press. The trials are ended after $40 \mathrm{~min}$ or after a failure response, meaning a failure to maintain wakefulness. The application of such tools and 
tests helps to evaluate fatigue, somnolence and vigilance, but normative data are limited except for those pertaining to the PVT.

There are actually no simple pharmacological tests to evaluate somnolence per se since no biological markers have yet been identified in the blood. The efficacy of the treatments on CSF hypocretin and histamine levels could be an interesting area to explore in research settings, but carry potential ethical limitations.

\section{Current treatments Modafinil}

Modafinil is a wakefulness-promoting agent that enhances the activity of wake-promoting neurons by increasing the extracellular concentration of dopamine [14,15]. This rise in extracellular dopamine may be caused by blockade of the dopamine transporter [16]. However, the precise mechanism of action of modafinil is unclear, with several studies outlining its possible action on dopamine, adrenalin, noradrenalin, serotonin and GABA systems [17-22].

It is recommended as a first-line therapy for sleepiness, since double-blind placebo-controlled trials of modafinil $200-400 \mathrm{mg}$ per day have shown a significant reduction of sleepiness $[23,24]$. It is a long-acting drug, with an elimination half-life of $13.8 \mathrm{~h}$ and a maximum concentration achieved in 2-4 h. The L-isomer has a shorter half-life than the R-isomer. The response to modafinil seems dependant on the catechol-O-methyltransferase genotype [25]. The drug is usually started at $100 \mathrm{mg}$ in the morning and $100 \mathrm{mg}$ at lunch for 1-2 weeks and increased to $200 \mathrm{mg}$ in the morning and $200 \mathrm{mg}$ at lunch. The most common adverse events are mild, including headache (13\%), nervousness $(8 \%)$ and nausea $(5 \%)$, with no evidence of tolerance and low potential for abuse. Modafinil can raise hepatic cytochrome P450 enzyme concentrations and increase the metabolism of oral contraceptives. Thus, a contraceptive containing at least $50 \mu \mathrm{g}$ of ethinylestradiol is recommended for women taking modafinil [10]. Teratology studies performed in animals did not provide any evidence of harm to the fetus; however, modafinil is not recommended in narcoleptic pregnant women. A systematic review and meta-analysis of the efficacy of modafinil in narcolepsy including nine trials involving 1054 patients in comparison with placebo showed that modafinil brings significant benefit in terms of elimination of excessive daytime sleepiness as assessed by Epworth Sleepiness Scale (ESS; -2.73 points),
MSLT (1.11 min) and MWT (2.82 min) [26]. A small increase in sleep latency may represent clinically significant improvements in wakefulness. However, modafinil does not completely restore wakefulness in patients with narcolepsy.

\section{Methylphenidate}

Methylphenidate is a potent stimulant that primarily blocks the reuptake of monoamines (mainly dopamine) and, unlike amphetamines, does not inhibit the vesicular monoamine transporter. It improves daytime sleepiness in patients with narcolepsy at daily doses of 10-60 mg, going up to $100 \mathrm{mg}$ daily at most for severe cases [27]. Only one class II evidence study showed significant improvement on daytime sleepiness in all dosages (10, 30 or $60 \mathrm{mg} /$ day) compared with baseline [28]. The clinical effect of methylphenidate is supposed to be similar to that of amphetamines. However, clinical experience would argue for a slight superiority of amphetamines. Adverse effects are the same as with amphetamines, but to a lesser degree. However, methylphenidate probably has a better therapeutic index than D-amphetamine, with less reduction of appetite or increase in blood pressure [29]. Methylphenidate has a relatively short duration of action (3-4 h) that is useful in cases where modafinil needs to be supplemented at a specific time of the day, or in situations where maximum alertness is required (e.g., while driving). Sustained-release formulations of methylphenidate are also available. It is contraindicated in pregnant women.

\section{Amphetamines}

Amphetamines including L-amphetamine, D-amphetamine (sulfate) and methamphetamine (chlorhydrate) have been used for narcolepsy since the 1930s [30]. At low doses, the main effect of amphetamine is to release dopamine and, to a lesser extent, norepinephrine through reverse efflux via monoaminergic transporters, the dopamine transporter and the norepinephrine transporter. At higher doses, monoaminergic depletion and inhibition of reuptake occurs. D-isomers have larger effects on dopamine transmission than L-isomers and have a greater stimulant effect. Methamphetamine, the methylated form of amphetamine, has a high CNS penetration that increases its wakefulness-promoting effect. Amphetamines are very effective for reducing sleepiness but induce frequent adverse effects including irritability, aggressiveness and, at worst, psychotic reactions, but insomnia, hypertension and 
abnormal movements can also occur at large doses (i.e., above $60 \mathrm{mg} /$ day) [31]. The potential for drug abuse or tolerance is important but surprisingly rare in patients with NC. No explanation for this is currently available, but the absence of hypocretin per se may explain the low rate of addiction.

\section{Sodium oxybate}

Sodium oxybate taken twice at night has a positive effect on excessive daytime sleepiness (see the later section on cataplexy).

\section{Other drugs}

Mazindol blocks both dopamine and adrenaline reuptake with some efficacy on sleepiness in small noncontrolled studies at the optimum daily dose of 2-3 $\mathrm{mg}$ [32]. Its elimination half-life is $10 \mathrm{~h}$. Adverse events are frequent, including weight loss, dry mouth, nervousness, constipation and, less frequently, nausea, vomiting, headache, dizziness and tachycardia. A careful cardiological follow-up is recommended. Mazindol has less potential for abuse and tolerance than amphetamines.

Selegiline is a complex drug that inhibits monoamine oxidase $\mathrm{B}$ and is metabolized into amphetamine, thereby having some stimulant effects [33].

Pemoline, a weak dopamine-reuptake inhibitor, is less efficacious than amphetamines, and, due to its high liver toxicity, it was therefore withdrawn from the market in most countries [34].

\section{Future treatments \\ Hypocretin replacement}

As most of the patients with NC are hypocretin ligand deficient, hypocretin-replacement therapy would probably be a promising strategy for both sleepiness and cataplexy. However, the uses of hypocretin-based treatments after peripheral administration have been disappointing as the peptides do not cross the BBB. Delivering hypocretin-1 intracerebroventricularly is likely to be most effective, but it is totally inappropriate for the treatment of patients on a long-term basis.

The BBB limits the distribution of systemically administered therapeutics to the CNS. Intranasal delivery is a noninvasive method that targets drugs to the brain along olfactory and trigeminal neural pathways, bypassing the BBB and minimizing systemic exposure and side effects. Recent reports in both rhesus monkeys and humans show some effects using intranasal hypocretin-1 administration. Intranasal hypocretin-1 was administered to sleep-deprived (30-36 h) rhesus monkeys immediately preceding testing on a short-term memory task, with results providing strong evidence for its effectiveness in alleviating cognitive deficits produced by loss of sleep [35]. A recent double-blind, randomized, placebocontrolled crossover design study applied hypocretin-1 intranasally to seven patients with NC and matched healthy controls, and measured olfactory performance [36]. Intranasal hypocretin-1 restores olfactory function in NC patients, but unfortunately, no data exist concerning potential effects on daytime sleepiness and cataplexy.

Hence, recent drug discovery efforts have identified small molecules with high potential for therapeutic effects, especially in pain modulation and anxiety domains [37].

Hypocretin cell transplantation might theoretically provide a cure for patients with $\mathrm{NC}$ even if disappointing results have been reported in other diseases, with graft rejection, low survival rate of implant and lack of supply for graft availability. These problems might be alleviated with improved stem cell technology in a long-term perspective for very severe cases resistant to pharmacological compounds. Finally, hypocretin gene therapy may also be of interest, but still has potentially dangerous side effects.

\section{Histaminergic $\mathrm{H}_{3}$ receptor inverse agonist}

In animal models, histaminergic neurons play a major role in wakefulness control. The firing of these neurons and the histamine release are maximal during wakefulness. The destruction and/or inhibition of these neurons reduce wakefulness. The activation of histaminergic neurons by an inverse agonist of the $\mathrm{H}_{3}$ receptor (which acts presynaptically and enhances histamine release) improves wakefulness in normal animals and decreases excessive daytime sleepiness in both orexin-knockout mice and human narcoleptics [38].

Several histaminergic $\mathrm{H}_{3}$ receptor antagonists/inverse agonists are currently being investigated. Pitolisant is an inverse $\mathrm{H}_{3}$ receptor agonist that effectively enhances histamine release and thus promotes wakefulness [38,39]. In a pilot single-blind study on 22 patients with $\mathrm{NC}$, pitolisant $40 \mathrm{mg}$ in the morning significantly improved daytime sleepiness $[38,39]$. The drug was considered safe on the studied population. The most frequent adverse events were 
headache, nausea and insomnia. If confirmed in larger studies, $\mathrm{H}_{3}$-receptor inverse agonists including pitolisant could become a treatment option for daytime sleepiness.

\section{Armodafinil}

Armodafinil is the R-enantiomer of modafinil. It primarily affects areas of the brain involved in controlling wakefulness. Plasma concentration following armodafinil administration lasts longer than that following modafinil administration, resulting in a more prolonged effect during the day and potential improvement in sleepiness in the late afternoon in patients with narcolepsy [40]. A single class I evidence study was performed in 196 patients randomized to receive armodafinil $150 \mathrm{mg}$, armodafinil $250 \mathrm{mg}$ or placebo once daily for 12 weeks [41]. Efficacy was assessed using the MWT and subjective tests. Compared with baseline measurements, the mean change from baseline at final visit for armodafinil was an increase of $1.3,2.6$ and $1.9 \mathrm{~min}$ in the $150,250 \mathrm{mg}$ and combined groups, respectively, compared with a decrease of $1.9 \mathrm{~min}$ for placebo. However, this study did not provide a comparison of modafinil and armodafinil.

\section{Thyrotropin-releasing hormone direct or indirect agonists}

Thyrotropin-releasing hormone (TRH) agonists could help in improving the waking system in narcolepsy [42]. TRH is a small peptide that may cross the $\mathrm{BBB}$ at high doses. TRH and TRH receptor type 2 are abundant in the reticular thalamic nucleus, where it is excitatory [43], while the major receptor subtype in the pituitary is type 1 . $\mathrm{TRH}$ at high doses and TRH agonists increase alertness and have been show to be wake-promoting and anticataplectic in the canine narcoleptic model [44]. However, older clinical trials, mainly on depression, reported little efficacy on mood and on alerting effects [45].

\section{Caffeine/paraxanthine}

Caffeine, an adenosine $A_{1}$ and $A_{2 a}$ receptor antagonist, is a widely consumed stimulant and often used to fight against daytime sleepiness. However, the wake-promoting potency of caffeine is often not strong enough for the treatment of narcolepsy, and high doses may induce side effects. Recently, paraxanthine, a metabolite of caffeine with stimulant properties, has been tested in a mouse model of narcolepsy, with results showing greater and longer-lasting wakepromoting potency, lower toxicity and lesser anxiogenic effects compared with caffeine [46].

\section{Cataplexy \& other symptoms of dissociated REM sleep}

Cataplexy is specific to narcolepsy and the best diagnostic marker of the disease. Cataplexy is defined by a sudden drop of muscle tone triggered by emotional factors, most often by positive emotions such as laughter, repartee, pleasant surprise (e.g., seeing a friend in the street) or by anger, but almost never by stress, fear or physical effort [3-5,47,48]. All striated muscles (but not the diaphragm) can be affected, causing the individual to fall in severe episodes. Cataplectic attacks are mostly limited to facial muscles or to the arms or legs, with dysarthria, facial flickering, jaw tremor, head or jaw dropping, dropping of objects or unlocking the knees. Patients remain fully conscious during the episodes. Deep tendon reflexes are transiently abolished during cataplexy, and H-reflex is absent [49,50]. The duration of cataplexy varies from a few seconds to several minutes. Its frequency varies from less than one episode per year to several episodes per day. Cataplexy worsens with poor sleep and fatigue. Patients may develop status cataplecticus, mainly after a withdrawal from anticataplectic antidepressants [51]. Neurophysiological and pharmacological studies indicate that regulation of cataplexy shares common mechanisms with REM sleep atonia.

Sleep-related hallucinations and sleep paralysis (i.e., symptoms of dissociated REM sleep) are nonspecific to narcolepsy but occur in 50\% of these patients [3,5]. Hypnagogic hallucinations can be unimodal, auditory (e.g., hearing a conversation in the room), visual (e.g., threatening figures, animals or passing shadows), or somesthetic (e.g., the feeling of being projected out of the body) or multimodal with complex scenarios, sometimes inducing confusion between dream and reality. Sleep paralysis is an inability to move and breathe normally, either at sleep onset or on awakenings (mainly from REM sleep) despite being mentally awake. It is frequently associated with hallucinations [52]. It can last from a few seconds to a few minutes and may be very frightening for the patients.

The frequency and the efficacy of the treatments of these dissociated REM sleep symptoms are difficult to evaluate. Diaries are useful to measure the frequency of the symptoms. However, the efficacy of the treatments can be increased by the adaptation of the patients to their symptoms. For example, some patients improve their cataplexies (frequency or severity) by avoiding strong emotions or laughing, among other similar approaches. 


\section{Current treatments}

Pharmacological experiments using canine narcolepsy and monoamine-uptake inhibitors have consistently demonstrated that adrenergicuptake inhibitors are most potent for reducing cataplexy, hallucinations and sleep paralysis, while dopamine-uptake inhibitors had little or no effect. The effectiveness of sodium oxybate was demonstrated for cataplexy attacks in humans, but also on daytime sleepiness and disturbed nocturnal sleep. Sodium oxybate and antidepressants are the most effective drugs for cataplexy in humans.

\section{Sodium oxybate}

$\gamma$-hydroxybutyrate, or sodium oxybate in its most recent designation, is approved by the EMA for the treatment of NC and by the US FDA for the treatment of cataplexy and excessive daytime sleepiness in patients with narcolepsy. Sodium oxybate is a natural metabolite of $\gamma$-aminobutyrate that acts as a neurotransmitter via its own receptors and via the stimulation of $\mathrm{GABA}_{\mathrm{B}}$ receptors [53]. However, the mechanism of action of GHB that accounts for its efficacy in treating the symptoms of narcolepsy is poorly understood. Despite its short elimination halflife of 40-60 min, the effect persists for much longer than this. At doses between 4.5 and $9 \mathrm{~g}$ nightly, sodium oxybate is effective in reducing both the frequency and intensity of cataplexy [54-56]. Randomized controlled studies of GHB efficacy have shown that it reduced cataplexy attacks. GHB reduced cataplexy attacks both on a daily and a weekly basis, nocturnal awakenings, daytime sleep attacks on a weekly basis, daytime sleepiness and sleep stage shift [54-56]. A significant impact was also observed for the slowwave sleep stages and it also improved the clinical global impression change score, in addition to with some evidence of effectiveness for episodes of sleep paralysis and hypnagogic hallucinations.

Patients should be instructed to start at $4.5 \mathrm{~g}$ of GHB (2.25 $\mathrm{g}$ at bedtime before sleeping and $2.25 \mathrm{~g}$ at $2 \mathrm{~h} 30 \mathrm{~min}-4 \mathrm{~h}$ later) for 2-4 weeks, increasing to $6 \mathrm{~g}$ in two equally divided doses over 4 weeks. After a check-up to assess the benefit:risk ratio, the dose can be increased to up to $9 \mathrm{~g}$. The benefit was significant after 4 weeks, highest after 8 weeks and was maintained during long-term therapy [57]. Patients show no evidence of tolerance, and unlike antidepressant-based therapies for cataplexy, interruption for sodium oxybate treatment did not result in a rebound of cataplexy. Adverse effects are dizziness, headache, nausea and, more rarely, depressive mood, enuresis and sleepwalking. Animal studies have shown no evidence of teratogenicity. However, the potential risk for humans is unknown, and sodium oxybate is not recommended during pregnancy. Sodium oxybate can also be used in association with antidepressant or stimulant therapy. Coadministration of sodium oxybate with modafinil is of interest in treating sleepiness in patients with narcolepsy [56]. Sodium oxybate should not be used in conjunction with alcohol. Patients should skip one or two doses if they have drunk any amount of alcohol.

The major problem with GHB is its nonmedical use. GHB is misused in athletes for its metabolic effects (growth hormone-releasing effects) and it has been used as a 'date rape' drug because of its rapid sedating effect. However, postmarketing follow-up studies indicate that abuse potential in patients with narcolepsy receiving sodium oxybate is low [58] and a risk-management program in Europe and in the USA permits the safe handling and distribution of the compound and minimizes the risk for diversion [59]. There is no clear evidence of the emergence of dependence in patients with $\mathrm{NC}$ taking sodium oxybate at therapeutic doses.

\section{Antidepressants}

Tricyclic antidepressants, selective serotonin-reuptake inhibitors (SSRIs) and selective serotoninand noradrenalin-reuptake inhibitors are widely used and are effective at treating cataplexy, sleep paralysis and hypnagogic hallucinations. However, their efficacy has never been assessed in placebocontrolled clinical trials. Tricyclic antidepressants are approved for the treatment of cataplexy at the national agency level of some European countries and SSRIs for a few other European countries. Neither tricyclic antidepressants nor SSRIs are approved for cataplexy by the FDA.

The anticataplectic effects of these drugs differ from their antidepressant effects in their rapid response to treat cataplexy (less than 1 week). The risk of cataplexy rebound or 'status cataplecticus' typically occurs if antidepressant intake is abruptly interrupted.

The dual norepinephrine- and serotoninreuptake inhibitor venlafaxine at doses of $75-300 \mathrm{mg} /$ day is particularly effective against cataplexy, with few side effects. Venlafaxine is widely used today with long-acting formulations that are ideal for covering the whole day, but lacks any published clinical evidence of efficacy. This recommendation is based on expert opinion only as venlafaxine was given to only four subjects in the published literature, for a period of $2-7$ months 
with doses up to $375 \mathrm{mg} /$ day [60]. Initial improvement in both excessive daytime sleepiness and cataplexy was reported by all subjects without significant adverse effects. However, increased heart rate and blood pressure are potential adverse effects. Tolerance was reported in one subject. Venlafaxine is not recommended in pregnant narcoleptic women.

Selective serotonin-reuptake inhibitors are also effective in the treatment of cataplexy (fluoxetine $20-60 \mathrm{mg} / \mathrm{day}$ and citalopram $20-40 \mathrm{mg} /$ day) $[1,61,62]$. Tricyclic medications include clomipramine (usually $10-25 \mathrm{mg}$, but occasionally $75-100 \mathrm{mg}$ in cases of persistent cataplexy), desipramine, imipramine and protriptyline, but adverse effects are frequent, in particular anticholinergic effects, but also orthostatic hypotension, anorexia, diarrhea, weight gain, tiredness and decreased libido.

Norepinephrine-reuptake inhibitors (viloxazine $100 \mathrm{mg} /$ day, reboxetine $2-10 \mathrm{mg} /$ day and atomoxetine $40-100 \mathrm{mg} /$ day) may also be effective against cataplexy, with only minor adverse effects. Novel targeted monoamine (norepinephrine especially)-reuptake inhibitors may be developed in the future to increase efficacy on cataplexy and to reduce side effects. Recently, a pilot study of duloxetine, a new norepinephrine- and serotonine-reuptake inhibitor, was conducted in three patients with NC. A rapid anticataplectic activity associated with excessive daytime sleepiness improvement was observed [63].

\section{Other treatments}

Both mazindol and selegiline have combined anticataplectic and stimulant properties [1]. In one study, $1-3 \mathrm{mg} /$ day of mazindol decreased cataplexy in $85 \%$ of the patients [64].

There is no established behavioral treatment of cataplexy, although patients can learn to avoid situations that trigger cataplexy attacks.

\section{Future treatments}

Narcolepsy with cataplexy is currently thought to be an autoimmune-mediated disorder. This hypothesis is based on the tight association of the HLA-DRB1*1501-DQB1*0602 haplotype together with the recent discovery of a strongly protective $D R B 1^{*} 1301-D Q B 1^{*} 0603$ haplotype [65], the finding of polymorphisms in the T-cell receptor- $\alpha$ locus [65] combined with a peripubertal age of onset [5], the presence of elevated antistreptolysin $\mathrm{O}$ and tribbles homolog 2 antibody levels [66] and the recent finding of higher serum levels of autoantibodies directed against hypocretin-1 [67]. Finally, the possibility that narcolepsy could be a rare side effect of the H1N1 influenza vaccination (Pandemrix vaccination [GlaxoSmithKline, Belgium], an H1N1 vaccination formulation containing the adjuvant ASO3) was recently reported and need to be confirmed [68]. Altogether, these results suggest that the loss of hypocretin-containing neurons in NC is attributable to an autoimmune process; however, the precise pathogenesis remains unclear.

\section{Immunomodulating treatments}

Based on the autoimmune hypothesis of narcolepsy, immune-based therapy such as steroids (in one patient), intravenous immunoglobulins (IVIg) and plasmapheresis (more invasive than IVIg with only one patient treated) have been proposed, with some promising results in a few cases [69,70].

In 2004, four patients with NC were treated with IVIg within a few months of acute onset of narcolepsy for three of them [68]. A clear improvement in the frequency and severity of cataplexy was observed. We recently reported on the first case of NC with undetectable CSF hypocretin-1 levels that completely reversed (clinically with main improvements in cataplexy and biologically with normalization of CSF hypocretin-1) after IVIg shortly after disease onset (only 15 days). These results support the idea that narcolepsy might be an autoimmune disease. Thus, an acute and focal inflammatory process could block hypocretin production without destroying neurons, explaining the reversibility of the disease at its beginning [71]. In summary, high-dose IVIg may be effective in some cases if applied at the early stages of NC development and acts mostly on the number of cataplectic attacks and severity of the cataplexy. Although needing replication in well-designed trials, a clear limitation of these treatments will be the need to intervene at disease onset (i.e., especially in childhood). Again, improving the knowledge of the process that kills the hypocretin neurons is required to provide more effective treatment and prevention strategies.

\section{Disturbed nocturnal sleep}

Nocturnal sleep is disturbed in a third of the patients. Typically, narcoleptic patients fall asleep almost instantly when they go to bed, but their subsequent sleep is interrupted by a high number of nocturnal awakenings, vivid frightening dreams and other phenomena such as REM sleep behavior disorder, periodic leg movement, obstructive sleep apnea (especially related to the increased obesity in NC) and other parasomnias. Different tools can be used to evaluate sleep quality: sleep diaries, actigraphy and 
polysomnography. This last technique is the most efficient for evaluating all the different sleep disorders that can be associated with narcolepsy.

\section{Current treatments \\ Sodium oxybate}

Sodium oxybate is the first-line treatment of disturbed nocturnal sleep in NC. Several studies reported a reduction in the number of nighttime awakenings with increased slow-wave sleep (see earlier). As patients with narcolepsy may present with a sleep apnea syndrome and sodium oxybate may have a role in worsening sleep breathing disorders, it should only be prescribed in patients who fully comply with nasal continuous positive airway pressure therapy [72] No systematic study of sodium oxybate on vivid and frightening dreams and REM sleep behavior disorder has ever been conducted.

\section{Other treatments}

Benzodiazepines (especially clonazepam) and related Z-drug hypnotics (zolpidem, zopiclone and zaleplon) may improve sleep disturbances in the same range as in the general population [1]. However, this benefit should be balanced with the possibility of increased daytime sleepiness, especially in the context of narcolepsy.

On the basis of available information, it is difficult to provide guidelines for the treatment of REM behavior disorder other than recommending conventional medications. Sleep apnea is more frequent in narcolepsy patients than in the general population, and should be treated with conventional therapy using a continuous positive airway pressure device, especially if sodium oxybate is planned to be prescribed. Periodic limb movements in sleep are also more prevalent in narcolepsy than in the general population. However, there is no documented benefit of treating these movements in patients with narcolepsy. Depressive patients with narcolepsy can be treated with antidepressant drugs and psychotherapy.

\section{Future treatments}

The current formulation of sodium oxybate has a short half-life, causing the patient to wake up during the night to take a second dose. The development of longer-acting sodium oxybate or derivates is ongoing. The currently studied slowwave sleep enhancers including novel $\mathrm{GABA}_{\mathrm{B}}$ agonists or modulators, but also some $\mathrm{GABA}_{\mathrm{A}}$ subtype-specific compounds (e.g., gaboxadol, even if the clinical development was stopped for primary insomnia) or $\mathrm{GABA}_{\mathrm{A}}$-reuptake inhibitors (e.g., tiagabine) may be developed in the future to improve night-time sleep in patients with NC.

\section{Conclusion}

Despite a major advancement in our understanding of the neurobiological basis of NC, its current therapy is only symptomatic and not effective enough against the disease as a whole. The discovery of hypocretin deficiency in humans has led to a new diagnostic test for narcolepsy and might open up new treatment perspectives. Novel and experimental treatments are needed, and several are under development.

\section{Future perspective}

Future therapeutic targets are clearly oriented towards hypocretin-replacement therapy, including hypocretin peptides or agonists, hypocretin neuron transplantation and hypocretin gene therapy, although some of these may have potentially dangerous side effects. Histamine (an arousal system) $\mathrm{H}_{3}$ antagonists, slow-wave sleep-enhancing treatments and immune-modulating drugs used at early stages of NC that may also modify the course of the disease have emerged as promising therapeutic options. Finally, even if clinical evidence shows that drugs approved in adult patients with narcolepsy are effective in children, the treatment of narcolepsy in children is still an area in great need of guidelines because of the absence of approved drug treatments or trials.

\section{Executive summary}

- Narcolepsy with cataplexy (NC) is a rare disabling sleep disorder, characterized by excessive daytime sleepiness, cataplexy (a sudden loss of muscle tone triggered by emotions), sleep paralysis, hypnagogic or hypnopompic hallucinations and disturbed night-time sleep.

- Pathophysiological studies have shown that NC is caused by the early loss of hypocretin/orexin neurons, probably triggered by an autoimmune mechanism.

- Main treatments of NC are modafinil or methylphenidate for daytime sleepiness, $\gamma$-hydroxybutyrate or antidepressants for cataplexy and other rapid eye movement-associated symptoms and $\gamma$-hydroxybutyrate for disturbed night-time sleep and also sleepiness and cataplexy.

- Future treatments may include more effective stimulants such as histamine $\left(\mathrm{H}_{3}\right)$ antagonists, but also immune-based therapy and hypocretin-replacement therapy. 


\section{Bibliography}

Papers of special note have been highlighted as:

- of interest

- of considerable interest

1. Dauvilliers Y, Billiard M, Montplaisir J. Clinical aspects and pathophysiology of narcolepsy. Clin. Neurophysiol. 114(11), 2000-2017 (2003).

2. American Sleep Disorders Association. The International Classification of Sleep Disorders. American Academy Of Sleep Medicine, IL, USA (2005).

3. Overeem S, Mignot E, van Dijk JG, Lammers GJ. Narcolepsy: clinical features, new pathophysiologic insights, and future perspectives. J. Clin. Neurophysiol. 18(2), 78-105 (2001).

4. Scammell TE. The neurobiology, diagnosis, and treatment of narcolepsy. Ann. Neurol. 53(2), 154-166 (2003).

5. Dauvilliers Y, Montplaisir J, Molinari N et al. Age at onset of narcolepsy in two large populations of patients in France and Quebec. Neurology 57(11), 2029-2033 (2001).

6. Peyron C, Faraco J, Rogers W et al. A mutation in a case of early onset narcolepsy and a generalized absence of hypocretin peptides in human narcoleptic brains. Nat. Med. 6(9), 991-997 (2000).

- Explores the role of hypocretins in human narcolepsy through histopathology and mutation screening of Hcrt, Hcrt 1 and Hcrt2, and shows that the Hcrt mutation is rare in humans (only reported in an atypical patient with very early onset of narcolepsy and absence of human leukocyte antigen $\left.D Q B 1^{*} 0602\right)$ and that almost all patients with narcolepsy have a global loss of hypocretin neurons.

7. Thannickal TC, Moore RY, Nienhuis R et al. Reduced number of hypocretin neurons in human narcolepsy. Neuron 27(3), 469-474 (2000).

- Demonstrates that human narcoleptics have an $85-95 \%$ reduction in the number of hypocretin neurons.

8. Crocker A, Espana RA, Papadopoulou M et al. Concomitant loss of dynorphin, NARP, and orexin in narcolepsy. Neurology 65(8), 1184-1188 (2005).

9. Blouin AM, Thannickal TC, Worley PF, Baraban JM, Reti IM, Siegel JM. Narp immunostaining of human hypocretin (orexin) neurons: loss in narcolepsy. Neurology 65(8), 1189-1192 (2005).

10. Dauvilliers Y, Arnulf I, Mignot E. Narcolepsy with cataplexy. Lancet 369(9560), 499-511 (2007).
- Up-to-date review on narcolepsy with cataplexy, focusing on symptoms, pathophysiology and treatments.

11. Arand D, Bonnet M, Hurwitz T, Mitler M, Rosa R, Sangal RB. The clinical use of the MSLT and MWT. Sleep 28(1), 123-144 (2005).

12. Doghramji K, Mitler MM, Sangal RB et al. A normative study of the maintenance of wakefulness test (MWT). Electroencephalogr. Clin. Neurophysiol. 103(5), 554-562 (1997).

13. Dinges DF, Kribbs NB. Sleep, Sleepiness and Performance. Monk TH (Ed.). Wiley, UK (1991).

14. Ferraro L, Tanganelli S, O'Connor WT, Antonelli T, Rambert F, Fuxe K. The vigilance promoting drug modafinil increases dopamine release in the rat nucleus accumbens via the involvement of a local GABAergic mechanism. Eur. J. Pharmacol. 306(1-3), 33-39 (1996).

15. de Saint Hilaire Z, Orosco M, Rouch C, Blanc G, Nicolaidis S. Variations in extracellular monoamines in the prefrontal cortex and medial hypothalamus after modafinil administration: a microdialysis study in rats. Neuroreport 12(16), 3533-3537 (2001).

16. Wisor JP, Nishino S, Sora I, Uhl GH, Mignot E, Edgar DM. Dopaminergic role in stimulant-induced wakefulness. J. Neurosci. 21(5), 1787-1794 (2001).

17. Saper CB, Scammell TE. Modafinil: a drug in search of a mechanism. Sleep 27(1), 11-12 (2004).

18. Mignot E, Nishino S, Guilleminault C, Dement WC. Modafinil binds to the dopamine uptake carrier site with low affinity. Sleep 17(5), 436-437 (1994).

19. Lin JS, Hou Y, Jouvet M. Potential brain neuronal targets for amphetamine-, methylphenidate-, and modafinil-induced wakefulness, evidenced by c-fos immunocytochemistry in the cat. Proc. Natl Acad. Sci. USA 93(24), 14128-14133 (1996).

20. Lin JS, Roussel B, Akaoka H, Fort P, Debilly G, Jouvet M. Role of catecholamines in the modafinil and amphetamine induced wakefulness, a comparative pharmacological study in the cat. Brain Res. 591(2), 319-326 (1992).

21. Gallopin T, Luppi PH, Rambert FA, Frydman A, Fort P. Effect of the wakepromoting agent modafinil on sleeppromoting neurons from the ventrolateral preoptic nucleus: an in vitro pharmacologic study. Sleep 27(1), 19-25 (2004).

22. Wisor JP, Eriksson KS. Dopaminergicadrenergic interactions in the wake promoting mechanism of modafinil. Neuroscience 132(4), 1027-1034 (2005).
23. Randomized trial of modafinil as a treatment for the excessive daytime somnolence of narcolepsy: US Modafinil in Narcolepsy Multicenter Study Group. Neurology 54(5), 1166-1175 (2000).

24. Randomized trial of modafinil for the treatment of pathological somnolence in narcolepsy. US Modafinil in Narcolepsy Multicenter Study Group. Ann. Neurol. 43(1), 88-97 (1998).

25. Dauvilliers Y, Neidhart E, Billiard M, Tafti M. Sexual dimorphism of the catechol-O-methyltransferase gene in narcolepsy is associated with response to modafinil. Pharmacogenomics J. 2(1), 65-68 (2002).

26. Golicki D, Bala MM, Niewada M, Wierzbicka A. Modafinil for narcolepsy: systematic review and meta-analysis. Med. Sci. Monit. 16(8), RA177-RA186 (2010).

27. Mitler MM, Hajdukovic R, Erman MK. Treatment of narcolepsy with methamphetamine. Sleep 16(4), 306-317 (1993).

28. Mitler MM, Shafor R, Hajdukovich R, Timms RM, Browman CP. Treatment of narcolepsy: objective studies on methylphenidate, pemoline, and protriptyline. Sleep 9(1 Pt 2), 260-264 (1986).

29. Guilleminault $C$, Carskadon $M$, Dement WC. On the treatment of rapid eye movement narcolepsy. Arch. Neurol. 30 (1), 90-93 (1974).

30. Prinzmetal M, Bloomberg W. The use of benzedrine for the treatment of narcolepsy. JAMA 105, 2051-2054 (1935).

31. Auger RR, Goodman SH, Silber MH, Krahn LE, Pankratz VS, Slocumb NL. Risks of high-dose stimulants in the treatment of disorders of excessive somnolence: a casecontrol study. Sleep 28(6), 667-672 (2005).

32. Alvarez B, Dahlitz M, Grimshaw J, Parkes JD. Mazindol in long-term treatment of narcolepsy. Lancet 337(8752), 1293-1294 (1991).

33. Mayer G, Ewert Meier K, Hephata K. Selegeline hydrochloride treatment in narcolepsy. A double-blind, placebocontrolled study. Clin. Neuropharmacol. 18(4), 306-319 (1995).

34. Ryan DH, Bray GA, Helmcke F et al. Serial echocardiographic and clinical evaluation of valvular regurgitation before, during, and after treatment with fenfluramine or dexfenfluramine and mazindol or phentermine. Obes. Res. 7(4), 313-322 (1999).

35. Deadwyler SA, Porrino L, Siegel JM, Hampson RE. Systemic and nasal delivery of orexin-A (hypocretin-1) reduces the effects of 
sleep deprivation on cognitive performance in nonhuman primates. J. Neurosci. 27(52), 14239-14247 (2007).

36. Baier PC, Weinhold SL, Huth V, Gottwald B, Ferstl R, Hinze-Selch D. Olfactory dysfunction in patients with narcolepsy with cataplexy is restored by intranasal Orexin A (hypocretin-1). Brain 131(Pt 10), 2734-2741 (2008).

37. Zaveri N. Peptide and nonpeptide ligands for the nociceptin/orphanin FQ receptor ORL1: research tools and potential therapeutic agents. Life Sci. 73(6), 663-678 (2003).

38. Lin JS, Dauvilliers Y, Arnulf I et al. An inverse agonist of the histamine $\mathrm{H}_{3}$ receptor improves wakefulness in narcolepsy: studies in orexin $^{-1-}$ mice and patients. Neurobiol. Dis. 30(1), 74-83 (2008).

39. Lin JS, Sergeeva OA, Haas HL. Histamine $\mathrm{H}_{3}$-receptors and sleep-wake regulation. J. Pharmacol. Exp. Ther. 336(1), 17-23 (2010).

- Review on the role of histamine in the maintenance of waking and the particular properties and locations of $\mathrm{H}_{3}$ receptors as a target for sleepiness in different sleep disorders.

40. Darwish M, Kirby M, Hellriegel ET, Robertson P Jr. Armodafinil and modafinil have substantially different pharmacokinetic profiles despite having the same terminal half-lives: analysis of data from three randomized, single-dose, pharmacokinetic studies. Clin. Drug Investig. 29(9), 613-623 (2009).

41. Harsh JR, Hayduk R, Rosenberg R et al. The efficacy and safety of armodafinil as treatment for adults with excessive sleepiness associated with narcolepsy. Curr. Med. Res. Opin. 22(4), 761-774 (2006).

42. Nishino S, Okuro M. Emerging treatments for narcolepsy and its related disorders. Expert Opin. Emerg. Drugs 15(1), 139-158 (2010).

43. Heuer H, Schafer MK, O’Donnell D, Walker P, Bauer K. Expression of thyrotropinreleasing hormone receptor 2 (TRH-R2) in the central nervous system of rats. J. Comp. Neurol. 428(2), 319-336 (2000).

44. Nishino S, Arrigoni J, Shelton J, Kanbayashi T, Dement WC, Mignot E. Effects of thyrotropin-releasing hormone and its analogs on daytime sleepiness and cataplexy in canine narcolepsy. J. Neurosci. 17(16), 6401-6408 (1997).

45. Bunevicius R, Matulevicius V. Short-lasting behavioural effects of thyrotropin-releasing hormone in depressed women: results of placebo-controlled study. Psychoneuroendocrinology 18(5-6), 445-449 (1993).

46. Okuro M, Fujiki N, Kotorii N, Ishimaru Y, Sokoloff P, Nishino S. Effects of paraxanthine and caffeine on sleep, locomotor activity, and body temperature in orexin/ataxin-3 transgenic narcoleptic mice. Sleep 33(7), 930-942 (2010).

47. Anic-Labat S, Guilleminault C, Kraemer HC, Meehan J, Arrigoni J, Mignot E. Validation of a cataplexy questionnaire in 983 sleepdisorders patients. Sleep 22(1), 77-87 (1999).

48. Thorpy MJ. Cataplexy associated with narcolepsy: epidemiology, pathophysiology and management. CNS Drugs 20(1), 43-50 (2006).

49. Guilleminault C. Cataplexy. In: Narcolepsy. Guilleminault C, Dement W, Passouant P (Eds). Spectrum, NY, USA (1976).

50. Overeem S, Reijntjes R, Huyser W, Lammers GJ, van Dijk JG. Corticospinal excitability during laughter: implications for cataplexy and the comparison with REM sleep atonia. J. Sleep Res. 13(3), 257-264 (2004).

51. Poryazova R, Siccoli M, Werth E, Bassetti CL. Unusually prolonged rebound cataplexy after withdrawal of fluoxetine. Neurology 65(6), 967-968 (2005).

52. Hishikawa Y, Shimizu T. Physiology of REM sleep, cataplexy, and sleep paralysis. $A d v$. Neurol. 67, 245-271 (1995).

53. Maitre M. The $\gamma$-hydroxybutyrate signalling system in brain: organization and functional implications. Prog. Neurobiol. 51(3), 337-361 (1997).

54. Lammers GJ, Arends J, Declerck AC, Ferrari MD, Schouwink G, Troost J. $\gamma$ hydroxybutyrate and narcolepsy: a doubleblind placebo-controlled study. Sleep 16(3), 216-220 (1993).

55. The US Xyremâ Multicenter Study Group. A randomized, double blind, placebocontrolled multicenter trial comparing the effects of three doses of orally administered sodium oxybate with placebo for the treatment of narcolepsy. Sleep 25(1), 42-49 (2002).

56. Black J, Houghton WC. Sodium oxybate improves excessive daytime sleepiness in narcolepsy. Sleep 29 (7), 939-946 (2006).

57. Robinson DM, Keating GM. Sodium oxybate: a review of its use in the management of narcolepsy. CNS Drugs 21(4), 337-354 (2007).

58. US Xyrem Multicenter Study Group. Sodium oxybate demonstrates long-term efficacy for the treatment of cataplexy in patients with narcolepsy. Sleep Med. 5(2), 119-123 (2004).

59. Fuller DE, Hornfeldt CS, Kelloway JS, Stahl PJ, Anderson TF. The Xyrem risk management program. Drug Saf. 27(5), 293-306 (2004).

60. Smith M, Parkes J, Dahlitz M. Venlafaxine in the treatment of narcoleptic syndrome. J. Sleep Res. 5, 217 (1996).
61. Abad VC, Guilleminault C. Emerging drugs for narcolepsy. Expert Opin. Emerg. Drugs 9(2), 281-291 (2004).

62. Mignot E, Nishino S. Emerging therapies in narcolepsy-cataplexy. Sleep 28(6), 754-763 (2005).

63. Izzi F, Placidi F, Marciani MG et al. Effective treatment of narcolepsy-cataplexy with duloxetine: a report of three cases. Sleep Med. 10(1), 153-154 (2009).

64. Iijima S, Sugita Y, Teshima Y, Hishikawa Y. Therapeutic effects of mazindol on narcolepsy. Sleep 9(1 Pt 2), 265-268 (1986).

65. Hallmayer J, Faraco J, Lin L et al. Narcolepsy is strongly associated with the T-cell receptor $\alpha$ locus. Nat. Genet. 41(6), 708-711 (2009).

66. Cvetkovic-Lopes V, Bayer L, Dorsaz S et al. Elevated Tribbles homolog 2-specific antibody levels in narcolepsy patients. J. Clin. Invest. 120(3), 713-719 (2010).

67. Deloumeau A, Bayard S, Coquerel Q et al. Increased immune complexes of hypocretin autoantibodies in narcolepsy. PLoS One 5(10) (2010).

68. Dauvilliers Y, Montplaisir J, Cochen V et al. Post-H1N1 narcolepsy-cataplexy. Sleep 33(11), 1428-1430 (2010).

69. Dauvilliers Y, Carlander B, Rivier F, Touchon J, Tafti M. Successful management of cataplexy with intravenous immunoglobulins at narcolepsy onset. Ann. Neurol. 56(6), 905-908 (2004).

70. Plazzi G, Poli F, Franceschini C et al. Intravenous high-dose immunoglobulin treatment in recent onset childhood narcolepsy with cataplexy. J. Neurol. 255(10), 1549-1554 (2008).

71. Dauvilliers Y, Abril B, Mas E, Michel F, Tafti M. Normalization of hypocretin-1 in narcolepsy after intravenous immunoglobulin treatment. Neurology 73(16), 1333-1334 (2009).

- The first case of narcolepsy with cataplexy with undetectable cerebrospinal fluid hypocretin-1 levels that completely reversed (clinically with main improvements in cataplexy and biologically with normalization of cerebrospinal fluid hypocretin-1) after intravenous immunoglobulin shortly following disease onset, results that give additional arguments that narcolepsy might be an autoimmune disease.

72. Feldman NT. Clinical perspective: monitoring sodium oxybate-treated narcolepsy patients for the development of sleep-disordered breathing. Sleep Breath. 14(1), 77-79 (2010). 


\section{$\underset{\substack{\text { Medscape } \\ \text { EDUA ATION }}}{\cos }$}

\section{Current and future therapeutic approaches in narcolepsy}

To obtain credit, you should first read the journal article. After reading the article, you should be able to answer the following, related, multiple-choice questions. To complete the questions (with a minimum $70 \%$ passing score) and earn continuing medical education (CME) credit, please go to www.medscape.org/journal/fnl. Credit cannot be obtained for tests completed on paper, although you may use the worksheet below to keep a record of your answers. You must be a registered user on Medscape.org. If you are not registered on Medscape.org, please click on the New Users: Free Registration link on the left hand side of the website to register. Only one answer is correct for each question. Once you successfully answer all post-test questions you will be able to view and/or print your certificate. For questions regarding the content of this activity, contact the accredited provider,
CME@medscape.net. For technical assistance, contactCME@webmd.net. American Medical Association's Physician's Recognition Award (AMA PRA) credits are accepted in the US as evidence of participation in CME activities. For further information on this award, please refer to http://www.ama-assn.org/ ama/pub/category/2922.html. The AMA has determined that physicians not licensed in the US who participate in this CME activity are eligible for AMA PRA Category 1 Credits $^{\mathrm{TM}}$. Through agreements that the AMA has made with agencies in some countries, AMA PRA credit may be acceptable as evidence of participation in CME activities. If you are not licensed in the US, please complete the questions online, print the AMA PRA CME credit certificate and present it to your national medical association for review.

\section{Activity evaluation: where 1 is strongly disagree and 5 is strongly agree.}

The activity supported the learning objectives.

The material was organized clearly for learning to occur.

The content learned from this activity will impact my practice.

The activity was presented objectively and free of commercial bias.

1. Your patient is a 34-year-old woman with excessive daytime sleepiness in whom the diagnosis of narcolepsy with cataplexy (NC) is being considered. On the basis of the review by Drs Cochen De Cock and Dauvilliers, which of the following statements about clinicopathologic features of NC is most likely correct?
A Sleep disturbances in NC predominantly affect non-rapid eye movement sleep
B Cataplexy is a sudden muscular rigidity triggered by emotions
C Sleep paralysis and hypnagogic or hypnopompic hallucinations may accompany NC
D In NC, there is a marked increase in hypocretin-1 levels in the cerebrospinal fluid and in the number of hypocretin neurons in post-mortem brain tissues

2. The patient described in question 1 is diagnosed with NC. On the basis of the review by Drs Cochen De Cock and Dauvilliers, which of the following statements about current treatment options is most likely correct?
A Antidepressants are often used for daytime sleepiness
B $\gamma$-hydroxybutyrate (sodium oxybate) may be used for both daytime sleepiness and for cataplexy
C Modafinil may be used for cataplexy
D Available treatments are curative and stop neuronal loss 
3. On the basis of the review by Drs Cochen De Cock and Dauvilliers, which of the following statements is most likely correct about treatments for NC likely to be available in the future?

$\square$ A Histamine $\left(\mathrm{H}_{3}\right)$ agonists are being tested as stimulants

$\square$ B Hypocretin antagonists may be therapeutically useful in NC

$\square$ C Immune-modulating drugs have no potential role

D Treatment of NC in children is still an area in great need of guidelines 